\title{
Synthesis of $\mathrm{Y}_{2} \mathrm{NiMnO}_{6}$ nanoparticles by ethylene glycol sol-gel method
}

\author{
Ming Lei \\ School of Optics and Electronic Information, Huazhong University of Science and Technology, \\ Wuhan, Hubei 430074, China \\ leiming_mb@163.com
}

Keywords: $\mathrm{Y}_{2} \mathrm{NiMnO}_{6}$; nanoparticles; multiferroics; sol-gel

Abstract. $\mathrm{Y}_{2} \mathrm{NiMnO}_{6}$ nanoparticles were synthesized via an ethylene glycol sol-gel method. Differential scanning calorimetry, thermogravimetric, $\mathrm{X}$-ray diffraction and environmental scanning electron microscopy were utilized to characterize precursors and derived powders. Single-phase $\mathrm{Y}_{2} \mathrm{NiMnO}_{6}$ nanoparticles were formed at $800^{\circ} \mathrm{C}$ for $2 \mathrm{~h}$. The analysis suggests that adding ethylene glycol can effectively suppress the formation of metal oxide and promote the formation of $\mathrm{Y}_{2} \mathrm{NiMnO}_{6}$. Compared to Polyvinyl alcohol, ethylene glycol is much better for the synthesis of $\mathrm{Y}_{2} \mathrm{NiMnO}_{6}$ via sol-gel method.

\section{Introduction}

$\mathrm{Y}_{2} \mathrm{NiMnO}_{6}$ with double perovskite structure have attracted much attention due to their unique properties, such as multiferroic, large magnetocapacitance, magnetoresistance and relaxor ferroelectricity [1-4]. Materials with such kinds of properties can be applied to novel devices, including memory and data storage devices [5-10]. $\mathrm{Y}_{2} \mathrm{NiMnO}_{6}$ can be synthesized via solid state reaction method. In the study of Tang et al., $\mathrm{Y}_{2} \mathrm{NiMnO}_{6}$ samples were sintered at $1400^{\circ} \mathrm{C}$ and the dielectric properties were measured [2]. The giant dielectric tunability was found in bulk $\mathrm{Y}_{2} \mathrm{NiMnO}_{6}$ around room temperature: a $4 \mathrm{~V} / \mathrm{mm}$ direct current electric field was able to suppress permittivity from 5059 to 826 at $10 \mathrm{kHz}$ and the tunability was more than $84 \%$ [2]. Such a high tunability means that, this kind of material holds great potential application in the field of microwave tunable devices. Further studies demonstrate that $\mathrm{Y}_{2} \mathrm{NiMnO}_{6}$ can also be prepared via polyvinyl alcohol (PVA) sol-gel method. In the work of Maiti et al., $\mathrm{Y}_{2} \mathrm{NiMnO}_{6}$ nanoparticles with the diameter 20nm were synthesized by a sol-gel method [3]. The $\mathrm{Y}_{2} \mathrm{NiMnO}_{6}$ powder was found single-phase with the calcination temperature $875^{\circ} \mathrm{C}$, which is much lower than the sintering temperature in the solid state reaction method. Moreover, the magnetic and dielectric properties of the nanoparticles were measured. The results prove that $\mathrm{Y}_{2} \mathrm{NiMnO}_{6}$ have the property of multiferroic, which are attracting enormous scientific interest. The strong magnetoelectric coupling of multiferroics is a very desirable property and required for an electric (magnetic) control of magnetic (electric) order parameter [1]. Therefore, the study on how to improve the synthesis of $\mathrm{Y}_{2} \mathrm{NiMnO}_{6}$ is meaningful.

In this paper, $\mathrm{Y}_{2} \mathrm{NiMnO}_{6}$ powder was prepared via a sol-gel method with different amount of ethylene glycol (EG). Differential scanning calorimetry, thermogravimetric, X-ray diffraction and environmental scanning electron microscopy were utilized to characterize precursors and derived powders. XRD patterns exhibit that more EG can effectively suppress the formation of metal oxide and promote the formation of $\mathrm{Y}_{2} \mathrm{NiMnO}_{6}$. Single-phase $\mathrm{Y}_{2} \mathrm{NiMnO}_{6}$ nanoparticles were obtained at $800^{\circ} \mathrm{C}$ for $2 \mathrm{~h}$. Compared to PVA, using EG as complexing agent can decrease the synthesis temperature and reduce the amount of complexing agent.

\section{Experimental Procedure}

$\mathrm{Y}_{2} \mathrm{NiMnO}_{6}$ nanoparticles were synthesized by using an EG sol-gel route. The raw chemicals for the synthesis were high purity $\mathrm{Y}_{2} \mathrm{O}_{3}, \mathrm{MnCO}_{3}$ and $\mathrm{Ni}\left(\mathrm{NO}_{3}\right)_{2} \cdot 6 \mathrm{H}_{2} \mathrm{O} . \mathrm{Y}_{2} \mathrm{O}_{3}, \mathrm{MnCO}_{3}$ powders were dissolved in nitric acid and mixed with high purity ethylene glycol. The ratios of hydroxyl groups of EG to metal ions $(\mathrm{OH} / \mathrm{M})$ are 1.5 and 5.2. After that, stoichiometric $\mathrm{Ni}\left(\mathrm{NO}_{3}\right)_{2} \cdot 6 \mathrm{H}_{2} \mathrm{O}$ was added to the solution. With continuous heating at $80^{\circ} \mathrm{C}$, viscosity of the solution increased and finally became a 
colloid and then the colloid was heated at $250^{\circ} \mathrm{C}$ for $2 \mathrm{~h}$. After expansion and combustion of the colloid, $\mathrm{Y}_{2} \mathrm{NiMnO}_{6}$ precursors were prepared. Lastly, these precursors were calcined at $500-1000^{\circ} \mathrm{C}$ for $2 \mathrm{~h}$ in air.

Simultaneous differential scanning calorimetry (DSC) and thermogravimetric (TG) analysis (STA449F3, Netzsch, Germany) were used to monitor decomposition and pyrolysis of the precursor at a heating rate of $10^{\circ} \mathrm{C} / \mathrm{min}$ in static air. Crystalline phases were identified by using powder X-ray diffraction with $\mathrm{CuK} \alpha$ radiation (Empyrean; PANalytical B.V., Netherlands). Environmental Scanning Electron Microscope (Quanta 200; FEI, Netherlands) was used to observe grain size and the morphology of $\mathrm{Y}_{2} \mathrm{NiMnO}_{6}$ powder.

\section{Results and Discussion}

Fig. 1 shows DSC-TG curves of the $\mathrm{Y}_{2} \mathrm{NiMnO}_{6}$ precursor $(\mathrm{OH} / \mathrm{M}=5.2)$. The weight loss between room temperature and $400^{\circ} \mathrm{C}$ is $27.4 \%$. A strong exothermic peak was observed between $260^{\circ} \mathrm{C}$ and $410^{\circ} \mathrm{C}$ in the DSC curve, accompanied by a sharp mass loss of about $20.5 \%$ in the TG curve which was caused by the decomposition of nitrates, the carbonization and volatilization of $\mathrm{EG}$ and the evolution of gases such as $\mathrm{CO}_{2}$. The second small exothermic peak around $870^{\circ} \mathrm{C}$, with a small mass loss of $1.3 \%$ in the TG curve, is associated with oxidation of residual organics.

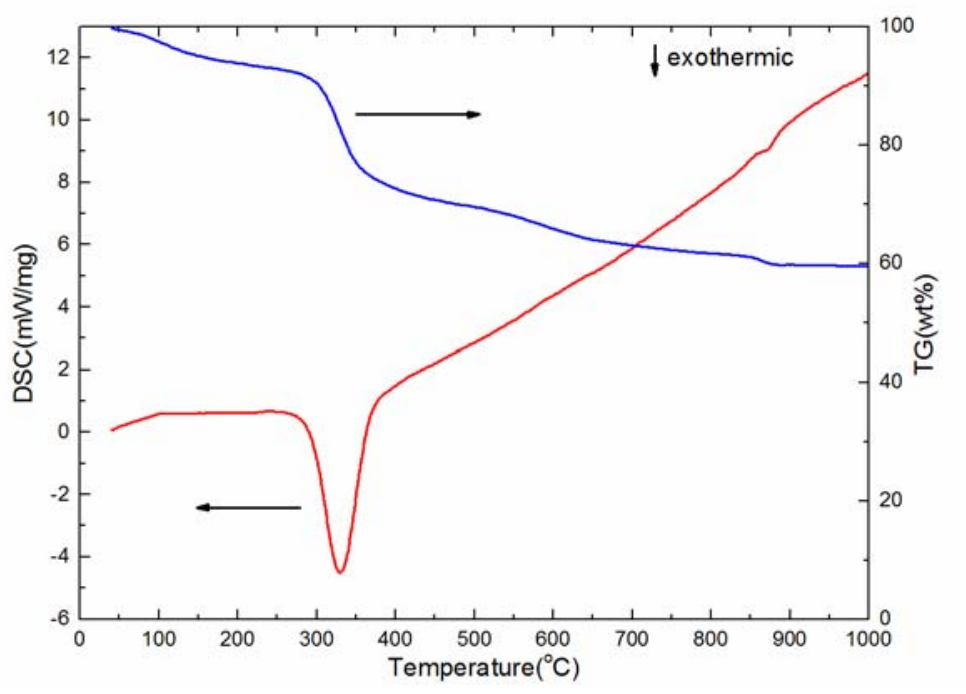

Fig. $1 \mathrm{DSC} / \mathrm{TG}$ curves of $\mathrm{Y}_{2} \mathrm{NiMnO}_{6}$ precursor $(\mathrm{OH} / \mathrm{M}=5.2)$.

Fig. 2 shows ESEM images of $\mathrm{Y}_{2} \mathrm{NiMnO}_{6}$ nanoparticles. In Fig. $2 \mathrm{a}, \mathrm{Y}_{2} \mathrm{NiMnO}_{6}(\mathrm{OH} / \mathrm{M}=1.5)$ were calcined at $900^{\circ} \mathrm{C}$ for $2 \mathrm{~h}$ and the diameter of particles is approximately 200nm. While in Fig. 2b, the diameter of $\mathrm{Y}_{2} \mathrm{NiMnO}_{6}$ nanoparticles $(\mathrm{OH} / \mathrm{M}=5.2)$, which were prepared at $800^{\circ} \mathrm{C}$ for $2 \mathrm{~h}$, is about 20-50nm. This size is quite close to the $\mathrm{Y}_{2} \mathrm{NiMnO}_{6}$ nanoparticles in the work of Maiti et al. [3].

Fig. 3 shows the XRD patterns of $\mathrm{Y}_{2} \mathrm{NiMnO}_{6}$ powder prepared by different $\mathrm{OH} / \mathrm{M}$ and calcined at various temperatures. In Fig. $3 \mathrm{a}$, we can notice that, from $500^{\circ} \mathrm{C}$ to $800^{\circ} \mathrm{C}$, the peaks of $\mathrm{Y}_{2} \mathrm{O}_{3}$ and $\mathrm{NiO}$ are observed without other phases. When the calcination temperature increases to $900^{\circ} \mathrm{C}$, the peaks from $\mathrm{Y}_{2} \mathrm{O}_{3}$ and $\mathrm{NiO}$ disappear, accompanied by the formation of $\mathrm{Y}_{2} \mathrm{NiMnO}_{6}$. No other phases are observed at $900^{\circ} \mathrm{C}$, so that the single-phase $\mathrm{Y}_{2} \mathrm{NiMnO}_{6}$ is prepared. In Fig. $3 \mathrm{~b}$, the $\mathrm{OH} / \mathrm{M}$ increases from 1.5 to 5.2 . From $500^{\circ} \mathrm{C}$ to $700^{\circ} \mathrm{C}$, the patterns exhibit no change and the powder maintains discrete state. The peaks of $\mathrm{Y}_{2} \mathrm{NiMnO}_{6}$ first appear at $800^{\circ} \mathrm{C}$ without other phases, so that the single-phase $\mathrm{Y}_{2} \mathrm{NiMnO}_{6}$ is prepared at $800^{\circ} \mathrm{C}$ in this figure. Generally, hydroxyl groups provide a polymeric network to hinder cation mobility allowing local stoichiometry to be maintained and minimizing precipitation of unwanted phases in the sol-gel method [11,12]. So that many metals can be stabilized at the polymer via interactions with hydroxy groups. With adding hydroxy groups, formation of metal oxide becomes harder which is consistent with the XRD patterns. As Fig. 3 shown, more EG can effectively suppress the formation of metal oxide and reduce the synthesis temperature of $\mathrm{Y}_{2} \mathrm{NiMnO}_{6}$. In the work of Maiti et al., single phase $\mathrm{Y}_{2} \mathrm{NiMnO}_{6}$ was obtained at $875^{\circ} \mathrm{C}$, while EG 
sol-gel method decrease this temperature to $800^{\circ} \mathrm{C}$. Reducing calcination temperature is very desirable for the synthesis of compounds. On the other hand, for the same OH/M, the amount of EG needed for the synthesis is less than PVA. Moreover, in our recent work, the effects of increasing PVA content on the synthesis of $\mathrm{Y}_{2} \mathrm{NiMnO}_{6}$ were analyzed [13]. Though adding PVA content could also promote the formation of $\mathrm{Y}_{2} \mathrm{NiMnO}_{6}$, it leads to the generation of $\mathrm{Y}(\mathrm{OH})_{3}$, which still exists at $900^{\circ} \mathrm{C}$. While adding EG content did not cause the formation of any impurity phase. All these evidences demonstrate that EG is better than PVA for the synthesis of $\mathrm{Y}_{2} \mathrm{NiMnO}_{6}$.
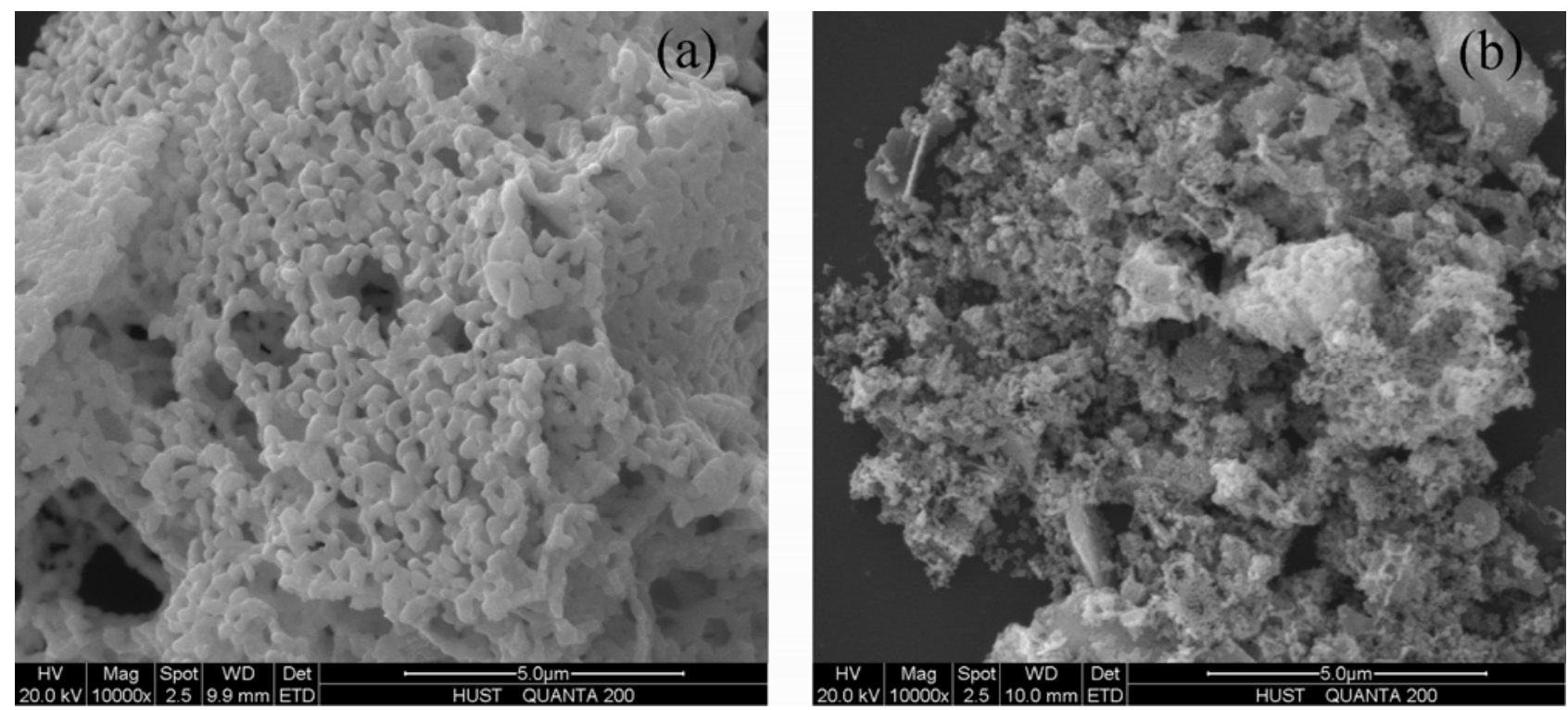

Fig. 2 ESEM micrographs of $\mathrm{Y}_{2} \mathrm{NiMnO}_{6}$ nanoparticles. (a) $\mathrm{Y}_{2} \mathrm{NiMnO}_{6}$ precursor $(\mathrm{OH} / \mathrm{M}=1.5)$ calcined at $900^{\circ} \mathrm{C}$, (b) $\mathrm{Y}_{2} \mathrm{NiMnO}_{6}$ precursor $(\mathrm{OH} / \mathrm{M}=5.2)$ calcined at $800^{\circ} \mathrm{C}$.
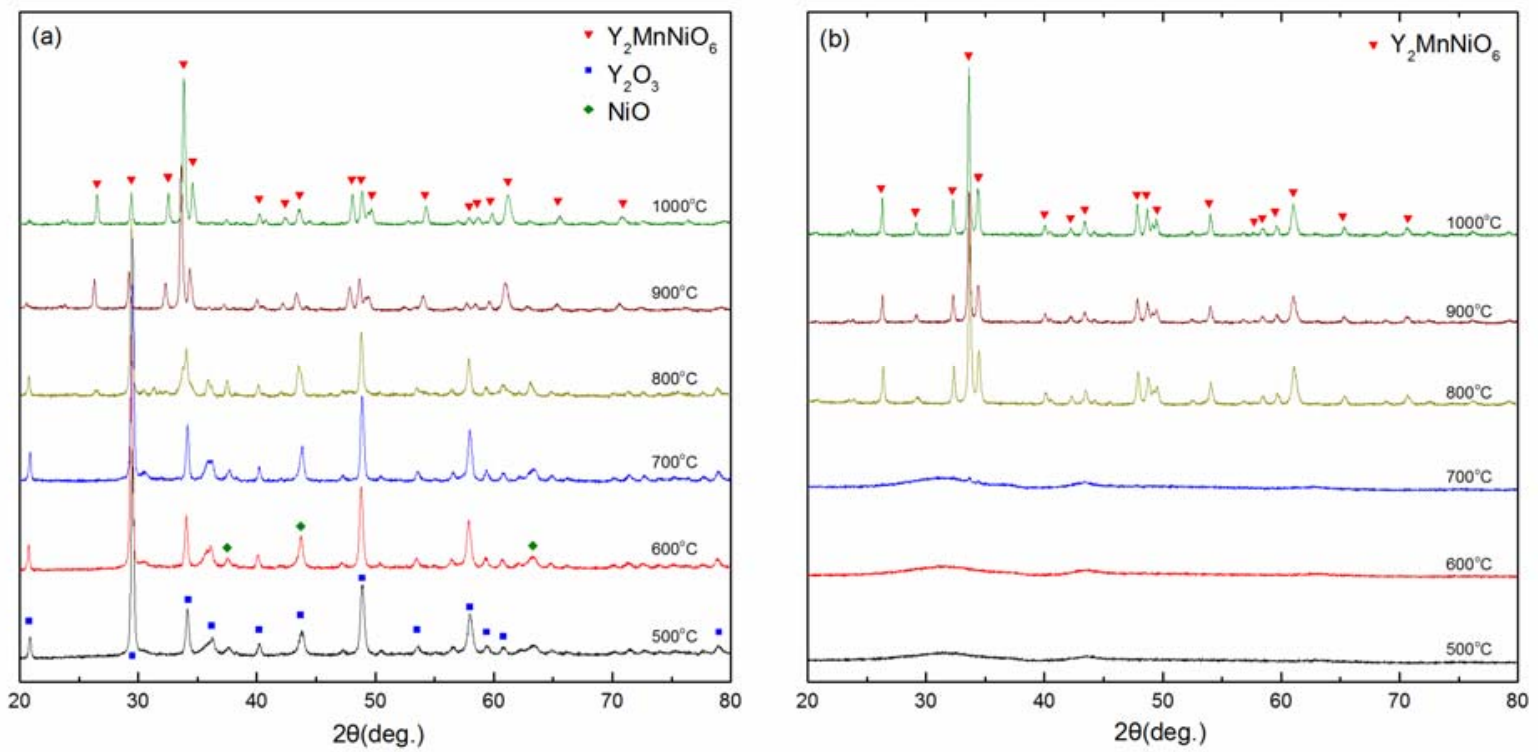

Fig. 3 XRD patterns of $\mathrm{Y}_{2} \mathrm{NiMnO}_{6}$ precursor calcined at various temperatures for $2 \mathrm{~h}$. (a) $\mathrm{OH} / \mathrm{M}=1.5$, (b) $\mathrm{OH} / \mathrm{M}=5.2$. 


\section{Conclusion}

$\mathrm{Y}_{2} \mathrm{NiMnO}_{6}$ nanoparticles were synthesized via an ethylene glycol sol-gel method. Phase pure $\mathrm{Y}_{2} \mathrm{NiMnO}_{6}$ powders of $20-50 \mathrm{~nm}$ in diameter were obtained at $800^{\circ} \mathrm{C}$ for $2 \mathrm{~h}$, without the formation of any intermediate phase. XRD analysis exhibits that more EG can effectively suppress the formation of metal oxide and promote the synthesis of $\mathrm{Y}_{2} \mathrm{NiMnO}_{6}$. Compared to PVA, using EG as complexing agent can decrease the synthesis temperature of $\mathrm{Y}_{2} \mathrm{NiMnO}_{6}$ and reduce the amount of complexing agent. Therefore, EG is preferable to PVA for the synthesis of $\mathrm{Y}_{2} \mathrm{NiMnO}_{6}$ via sol-gel method.

\section{References}

[1] S. Kumar, G. Giovannetti, J.V.D. Brink and S. Picozzi: Phys. Rev. B Vol. 82 (2010), p. 134429

[2] M.H. Tang, Y.G. Xiao, B. Jiang, J.W. Hou, J.C. Li and J. He: Appl. Phys. A Vol. 105 (2011), p. 679

[3] R.P. Maiti, S. Dutta, M. Mukherjee, M.K. Mitra and D. Chakravorty: J. Appl. Phys. Vol. 112 (2012), p. 044311.

[4] R.B.M. Filho, A.P. Ayala and C.W.A. Paschoal: Appl. Phys. Lett. Vol. 102 (2013), p. 192902

[5] T. Goto, T. Kimura, G. Lawes, A. Ramirez and Y. Tokura: Phys. Rev. Lett. Vol. 92 (2004), p. 257201

[6] K.F. Wang, J.M. Liu and Z.F. Ren: Adv. Phys. Vol. 58 (2009), p. 321

[7] M.P. Singh, K.D. Truong and P. Fourimen: J. Appl. Phys. Vol. 107 (2010), p. 09D917

[8] C.N. Li, B.X. Liu, Y.Y. He, C. Lv, H. He and Y.B. Xu: J. Alloys Comp. Vol. 590 (2014), p. 541

[9] S.W. Cheong and M. Mostovoy: Nature Mater. Vol. 6 (2007), p. 13

[10]R. Ramesh and N.A. S paldin: Nature Mater. Vol 6 (2007), p. 21

[11]M.A. Gulgun, M.H. Nguyen and W.M. Kriven: J. Am. Ceram. Soc. Vol. 82 (1999), p. 556

[12]J.S. Feng, T. Liu, Y.B. Xu, J.Y. Zhao and Y.Y. He: Ceram. Int. Vol. 37 (2011), p.1203

[13]M. Lei, Z. He, Z.J. Feng and Y.B. Xu: J. Sol-gel Sci. Techn. Vol. 76 (2015), p. 204 